\title{
INTERFACIAL SHEAR STRENGTH OF CARBON FIBER- REINFORCED POLYPROPYLENE USING UNEVEN CARBON FIBER UNDER A HOT-WET ENVIRONMENT FOR LONG-TERM SAFETY OF VEHICLES
}

\author{
KENICHI TAKEMURA ${ }^{1}$, MAO MOCHIZUKI ${ }^{1} \&$ HIDEAKI KATOGI $^{2}$ \\ ${ }^{1}$ Department of Mechanical Engineering, Kanagawa University, Japan \\ ${ }^{2}$ Department of Human Environmental Sciences, Jissen Women's University, Japan
}

\begin{abstract}
We have previously reported on the improvement of the interfacial shear strength of carbon fiberreinforced polypropylene (CFRPP) using carbon fiber with added resin particles (uneven carbon fiber). This study was conducted to assess the interfacial shear strength of CFRPP with uneven carbon fiber under a hot-wet environment for long-term safety of vehicles. The matrix was maleic anhydride grafted polypropylene. The matrix concentration was $10 \%$. Reinforcement was done with uneven carbon fiber. Water absorption tests of CFRPP were conducted using uneven carbon fiber. The range of water temperature was from room temperature (RT) to $80^{\circ} \mathrm{C}$. The maximum immersion time was 112 days. After water absorption testing, a micro-debonding test of CFRPP using uneven carbon fiber was conducted at RT. Fracture surfaces of carbon fibers were observed using scanning electron microscopy (SEM). Results show that when the maximum immersion time was 112 days, interfacial shear strength of water-immersed CFRPPs using uneven carbon fiber at RT, $50^{\circ} \mathrm{C}$ and $80^{\circ} \mathrm{C}$ decreased by $54 \%, 94 \%$ and $96 \%$ respectively, compared with that of non-immersed CFRPP using uneven carbon fiber. However, interfacial shear strengths of water-immersed CFRPPs using even and uneven carbon fiber under $50^{\circ} \mathrm{C}$ and $80^{\circ} \mathrm{C}$ showed almost no change at 112 days. SEM observations revealed large resin particles on the fracture surface of carbon fiber at temperatures higher than $50^{\circ} \mathrm{C}$. Large resin particles and matrix on fracture surface of carbon fiber were found at $80^{\circ} \mathrm{C}$. The viscoelasticity and interfacial adhesion property of water absorbing polymer matrix probably decreased when CFRPP using uneven carbon fiber was immersed at temperatures higher than $50^{\circ} \mathrm{C}$. Therefore, the interfacial shear strength of CFRPP using uneven carbon fiber was strongly affected because of water absorption by polymer matrix and water penetration into interface between fiber and polymer matrix under a hot-wet environment.

Keywords: CFRPP, hot-wet environment, interfacial shear strength, long term, maleic anhydride grafted polypropylene, uneven carbon fiber.
\end{abstract}

\section{INTRODUCTION}

FOMM Co. Ltd. announced a new concept for a microelectric vehicle in 2016 with a flotation system as a countermeasure against flood damage [1]. The microelectric vehicle is used under hot, rainy, and moist environments. The maximum temperature of the dashboard in vehicle reaches about $85^{\circ} \mathrm{C}$ [2]. Recently, control of motor temperatures in electric vehicle has been studied as a countermeasure against high temperatures [3], [4]. Mechanical properties of structural materials of microelectric vehicles under high temperature and water environments should be clarified for long-term safety. Carbon fiberreinforced polypropylene (CFRPP) is used as a structural material for microelectric vehicles because carbon fiber has high specific strength and modulus. Therefore, many researchers have reported on CFRPP mechanical properties and molding methods [5]-[13]. Nevertheless, no report of the literature describes a study of CFRPP mechanical properties under temperature and water environments. 
Katogi and Takemura [14] reported the effects of water temperature on the interfacial shear strength of CFRPP when using uneven carbon fiber for improvement. When the immersion time was a single day, the interfacial shear strength of CFRPP using uneven carbon fiber was affected by water temperature.

Nevertheless, few research papers describe interfacial shear strength of CFRPP using uneven carbon fiber under a long-term hot-wet environment. This study examined the interfacial shear strength of CFRPP using uneven carbon fiber under a hot-wet environment to ensure long-term safety.

\section{MATERIALS AND SPECIMENS}

\subsection{Materials}

Matrix was maleic anhydride grafted polypropylene (MAPP, Umex 1010; Sanyo Chemical Industries Ltd.). The MAPP concentration was 10\%. Reinforcements were even and uneven carbon fibers (Sekisui Chemical Co. Ltd.).

\subsection{Specimens}

Specimens for micro-debonding test were made using a soldering iron. The molding temperature was $180^{\circ} \mathrm{C}$. The CFRPP specimen shape using uneven carbon fiber was Ushaped [14]. Matrix was adhered to surface of carbon fiber like a spherical shape. The embedding length of specimen for micro-debonding tests was from $100 \mu \mathrm{m}$ to $300 \mu \mathrm{m}$.

\section{TESTING METHODS}

\subsection{Water absorption testing}

Water absorption tests of CFRPP were conducted in distilled water using a constant drying oven. The water temperature range was from room temperature (RT) to $80^{\circ} \mathrm{C}$. The maximum immersion time was 112 days.

\subsection{Micro-debonding testing}

Before and after water immersion, micro-debonding tests of CFRPPs using non-immersed and uneven carbon fiber were conducted using a tensile testing machine (RTC-1250A; A\&D Co. Ltd.). A jig made in our laboratory was used for micro-debonding tests. The environmental temperature was RT. The crosshead speed was $0.1 \mathrm{~mm} / \mathrm{min}$. After microdebonding test, the fracture surface of carbon fiber was observed using scanning electron microscopy (SEM, S-400; Hitachi High-Technologies Corp. and VE7200; Keyence Co.).

\section{RESULTS AND DISCUSSION}

4.1 Interfacial shear strength of CFRPP using uneven carbon fiber under a hot-wet environment

Figs 1-3 show the interfacial shear strength of CFRPP using uneven carbon fiber under a hot-wet environment. Interfacial shear strengths of CFRPPs using even and uneven carbon fibers decreased rapidly under all conditions after water immersion for one day. Interfacial shear strengths of CFRPPs using even and uneven carbon fibers decreased slowly under all 


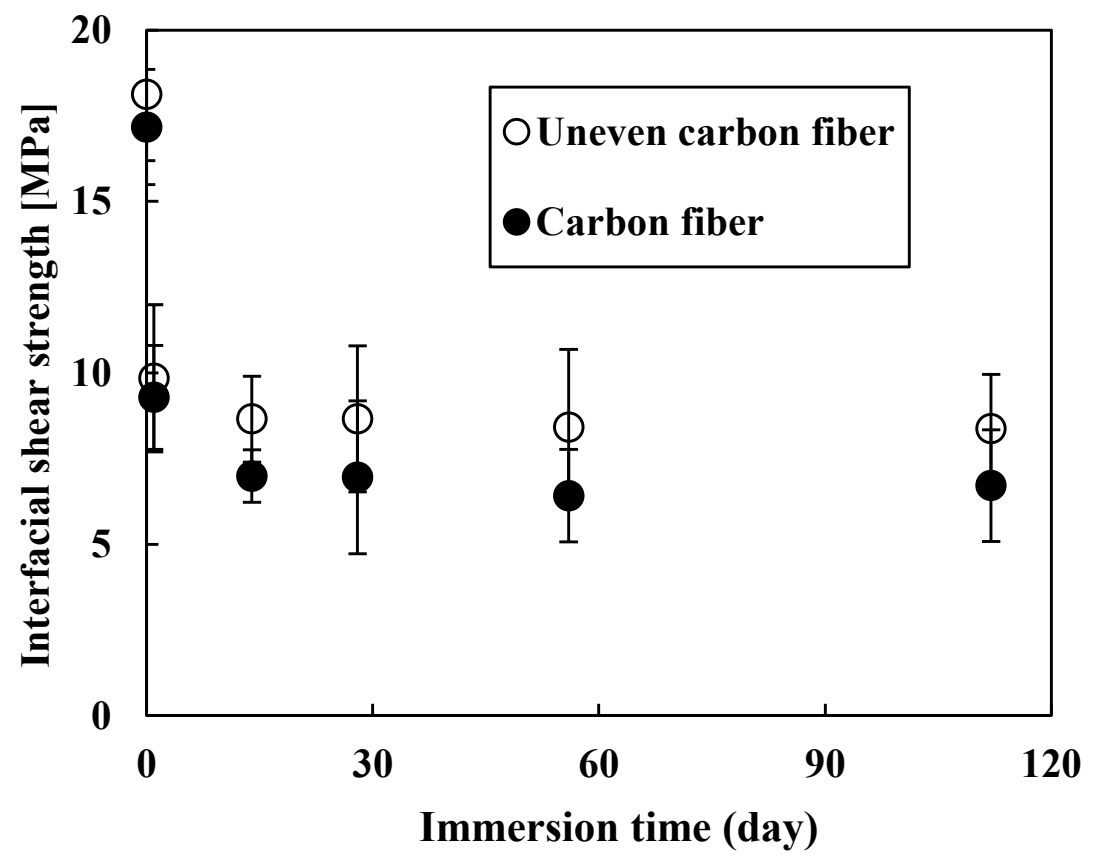

Figure 1: Interfacial shear strengths of CFRPPs using even and uneven carbon fibers (RT).

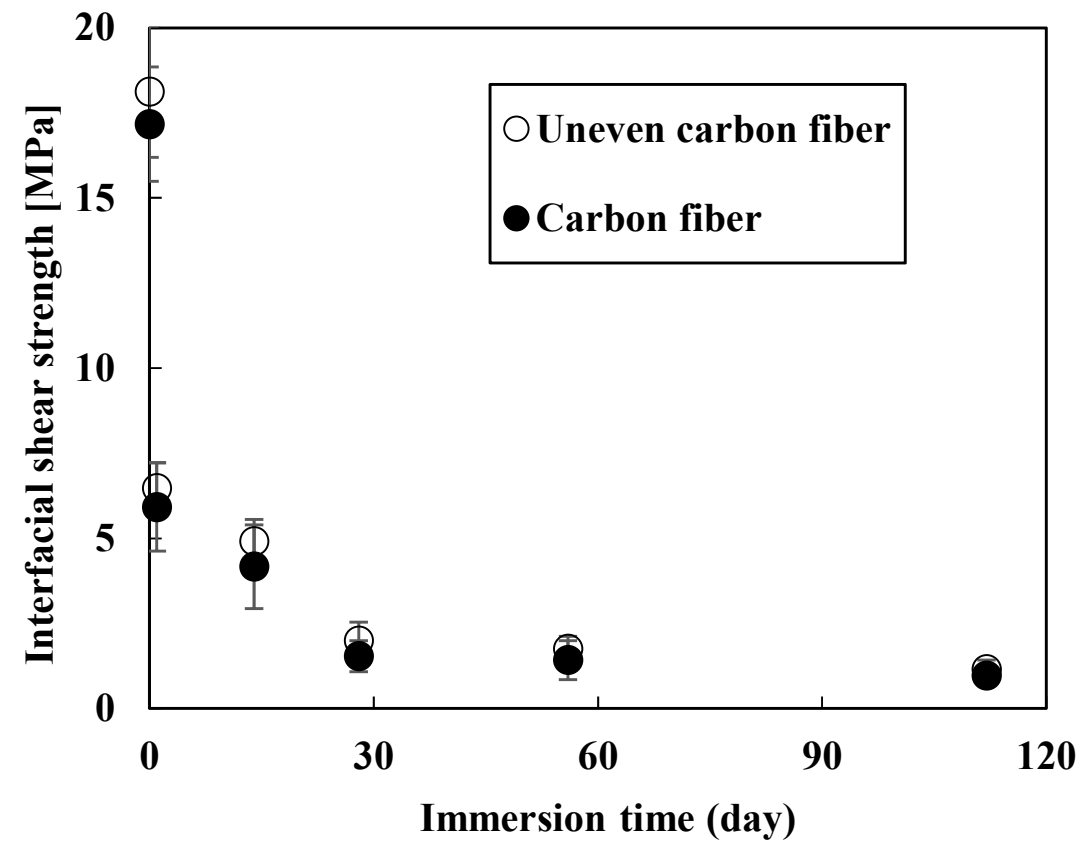

Figure 2: Interfacial shear strengths of CFRPPs using even and uneven carbon fibers $\left(50^{\circ} \mathrm{C}\right)$. 


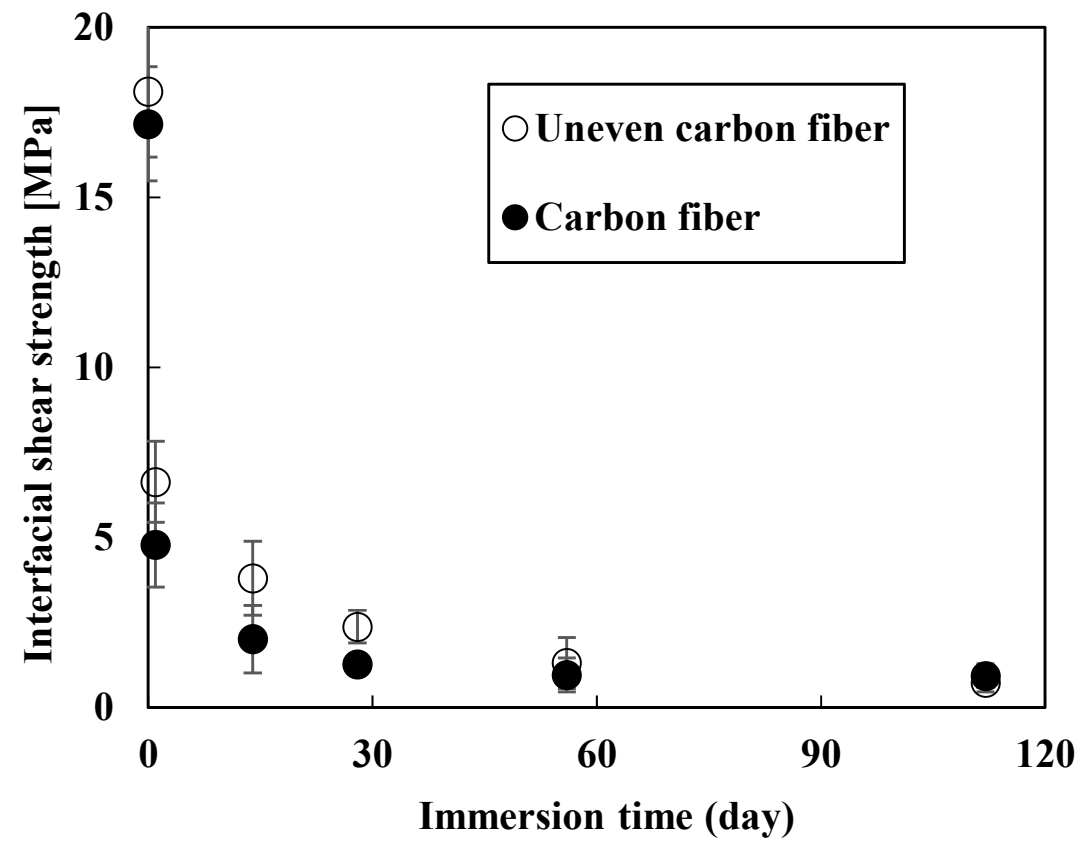

Figure 3: Interfacial shear strengths of CFRPPs using even and uneven carbon fibers $\left(80^{\circ} \mathrm{C}\right)$.

conditions with an increase of immersion time until 28 days. Subsequently, the interfacial shear strengths of CFRPPs using even and uneven carbon fibers under all conditions remained almost unchanged with an increase of the immersion time.

When the water temperature was RT, the interfacial shear strength of CFRPP using uneven carbon fiber was larger than that of CFRPP using even carbon fiber under all immersion times. When the water temperature was higher than $50^{\circ} \mathrm{C}$, the interfacial shear strength of CFRPP using uneven carbon fiber was greater than that of CFRPP using uneven carbon fiber after water immersion until 28 days. The interfacial shear strength of CFRPP using uneven carbon fiber was almost no different from that of CFRPP using even carbon fiber after water immersion over 56 days. For maximum immersion time of 112 days, interfacial shear strength of water-immersed CFRPPs using uneven carbon fiber at RT, $50^{\circ} \mathrm{C}$ and $80^{\circ} \mathrm{C}$ decreased by $54 \%, 94 \%$ and $96 \%$, respectively, compared with that of nonimmersed CFRPP using uneven carbon fiber.

It is possible that water penetration into the interface between fiber and polymer matrix occurred easily because of the water temperature [13]. The polymer matrix has a hydrophilic segment. Therefore, the interfacial adhesion property of the polymer matrix probably decreased with increased immersion time because of the chemical reaction of the hydrophilic segment of the polymer matrix under water temperature. However, the interfacial shear strength of CFRPPs using uneven carbon fibers after water immersion for the long term was not changed because debonding at the fiber and polymer matrix mainly occurred at temperatures higher than $50^{\circ} \mathrm{C}$. 
4.2 Hot-wet environment effects on the CFRPP fracture surface using uneven carbon fibers

Fig. 4 shows fracture surfaces of CFRPPs using even and uneven carbon fibers before water immersion. Before water immersion, the CFRPP fracture surface using even carbon fiber became smooth. However, small resin particles and the matrix on the fracture surface of CFRPP using uneven carbon fiber were found before water immersion.

Figs 5-7 depict the CFRPP fracture surface using even carbon fiber under a hot-wet environment. Figs 8-10 show fracture surfaces of CFRPP using uneven carbon fiber under a hot-wet environment. The fracture surface of water-immersed CFRPP using even carbon fiber almost became smooth under all conditions except for water immersion for one day at RT. When the water temperature was higher than $50^{\circ} \mathrm{C}$, large resin particles were found on the fracture surface of water-immersed CFRPP using uneven carbon fiber at one day and 112 days. Much matrix material on the fracture surface of CFRPP using uneven carbon fiber at $80^{\circ} \mathrm{C}$ was often found compared with that of CFRPP using uneven carbon fiber at $50^{\circ} \mathrm{C}$. Furthermore, matrix residue on the CFRPP fracture surface using uneven carbon fiber at 112 days was more than that of CFRPP using uneven carbon fiber at one day when the water temperature was $80^{\circ} \mathrm{C}$.

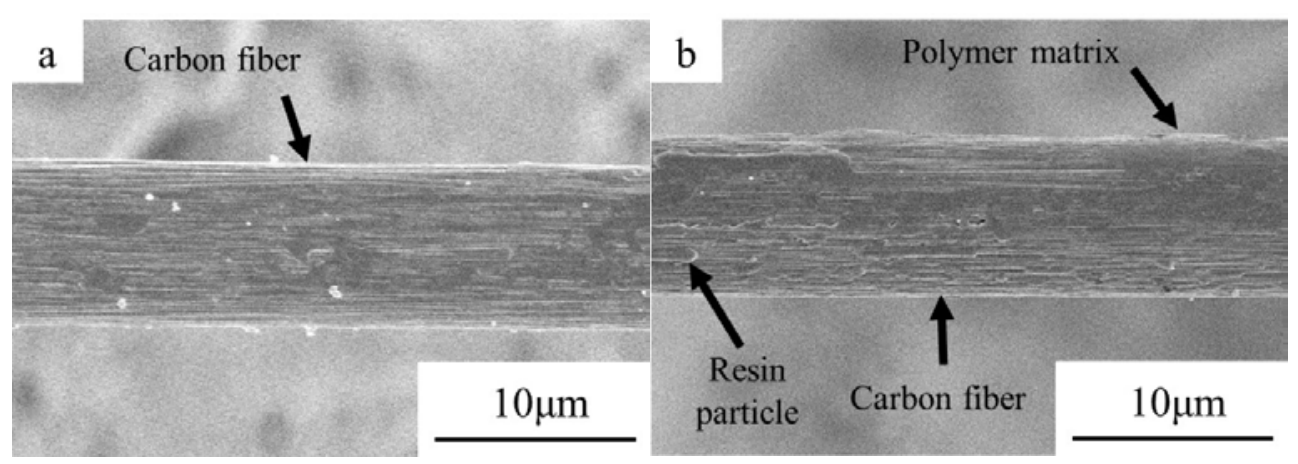

Figure 4: Fracture surface of CFRPP before water immersion. (a) Carbon fiber; and (b) Uneven carbon fiber.
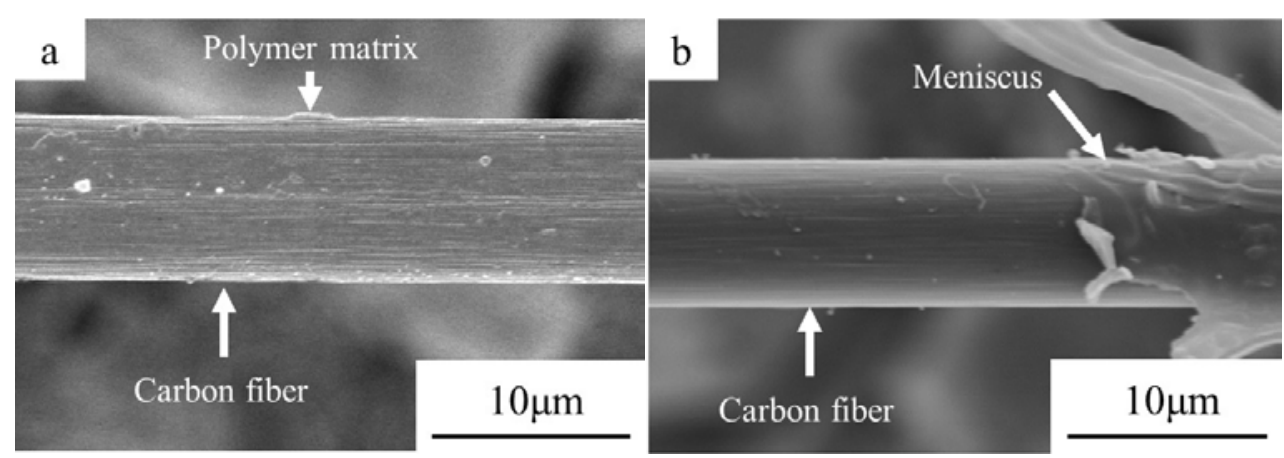

Figure 5: Fracture surfaces of CFRPPs using even carbon fibers (RT). (a) 1 day; and (b) 112 days. 


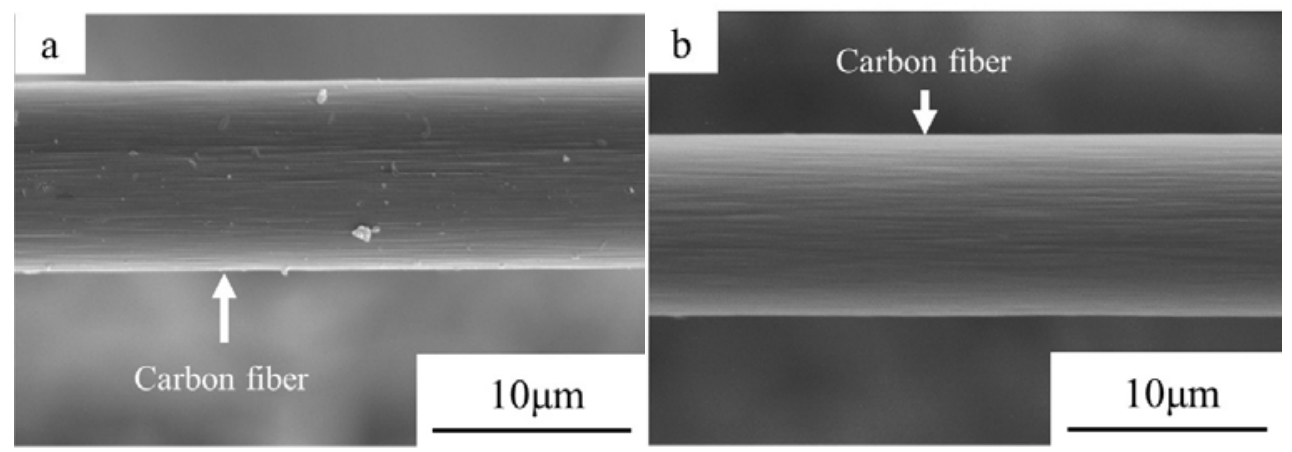

Figure 6: Fracture surfaces of CFRPPs using even carbon fibers $\left(50^{\circ} \mathrm{C}\right)$. (a) 1 day; and (b) 112 days.
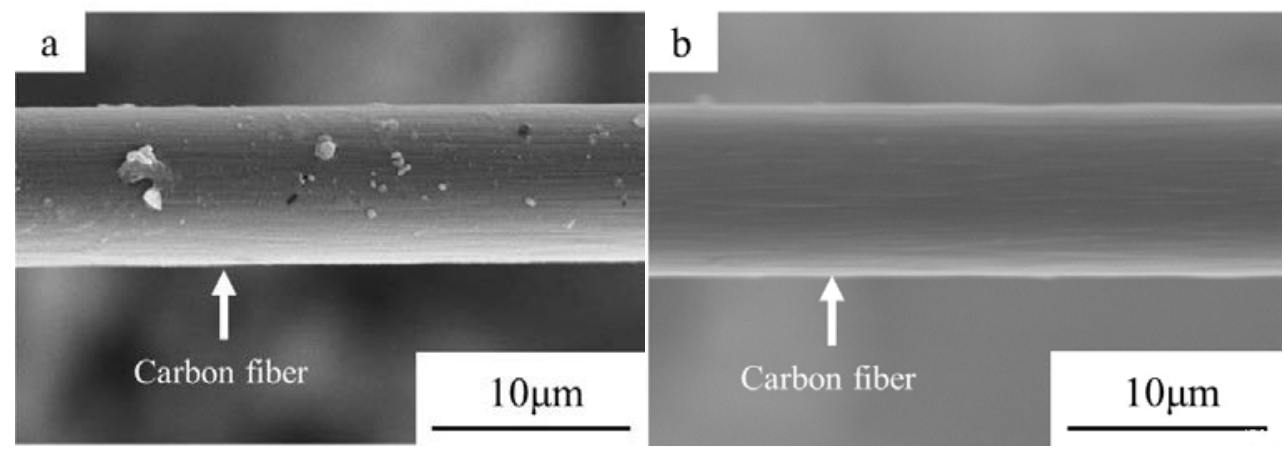

Figure 7: Fracture surfaces of CFRPPs using even carbon fibers $\left(80^{\circ} \mathrm{C}\right)$. (a) 1 day; and (b) 112 days.
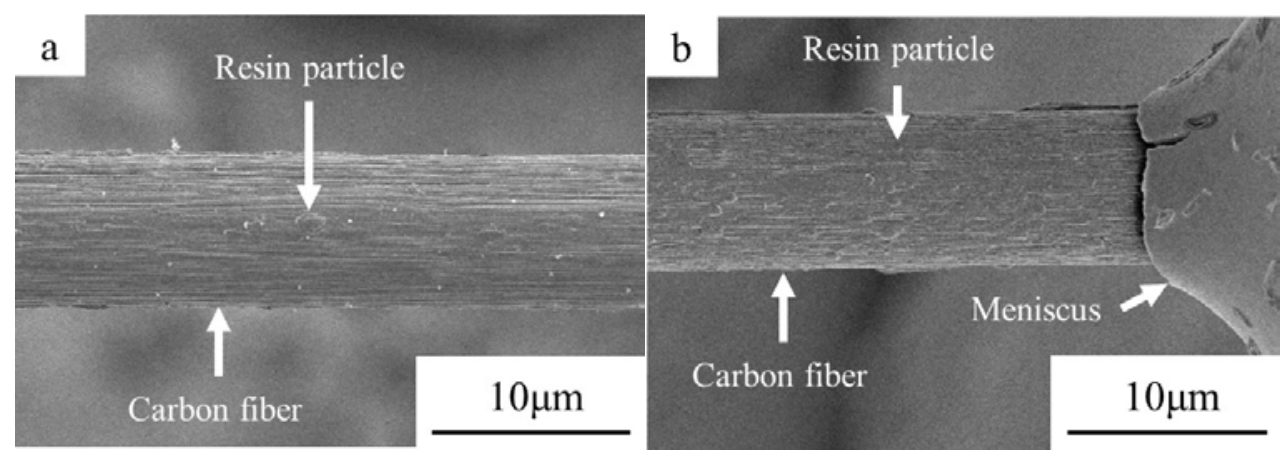

Figure 8: Fracture surfaces of CFRPPs using uneven carbon fibers (RT). (a) 1 day; and (b) 112 days. 


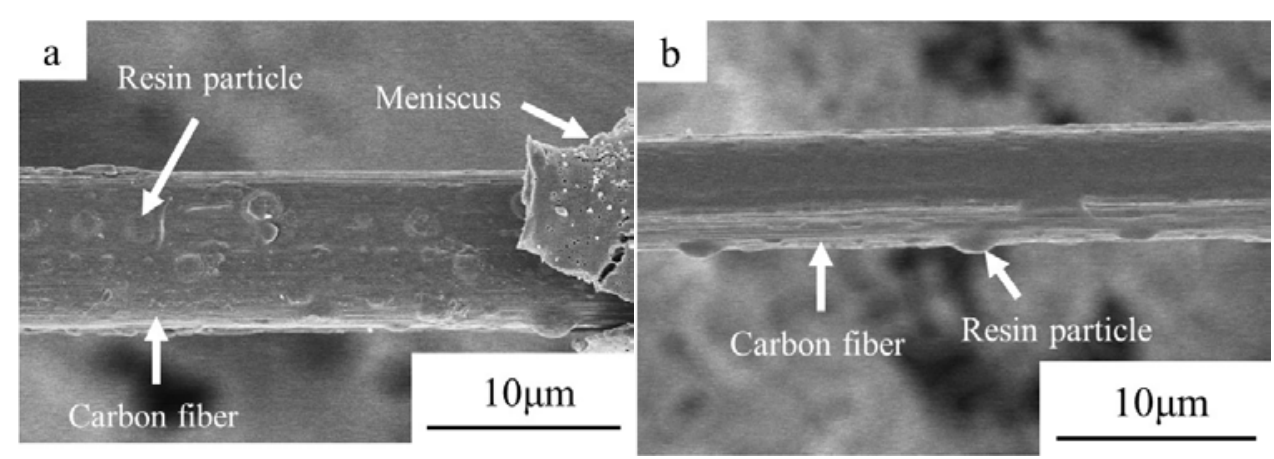

Figure 9: Fracture surfaces of CFRPPs using uneven carbon fibers $\left(50^{\circ} \mathrm{C}\right)$. (a) 1 day; and (b) 112 days.
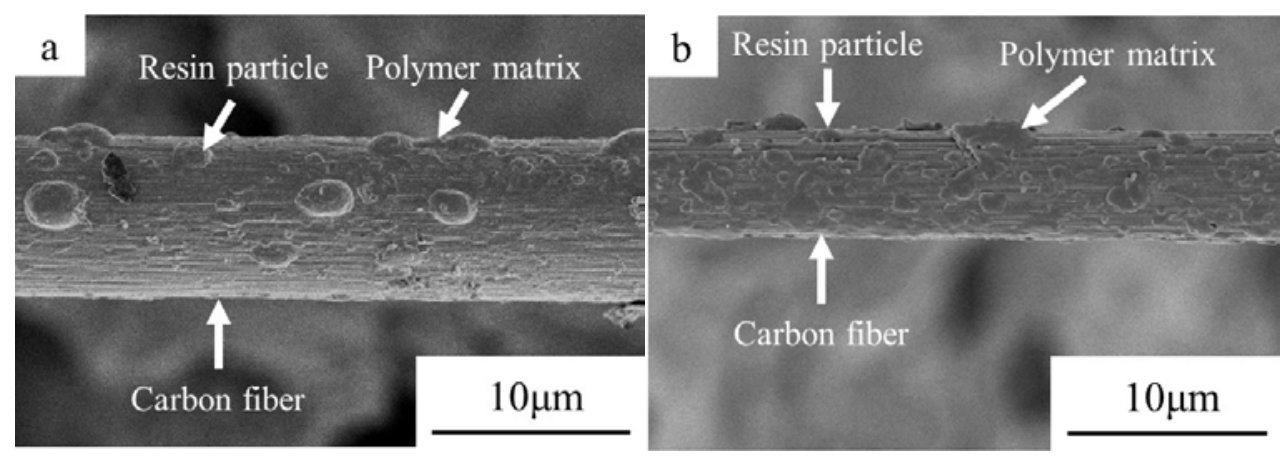

Figure 10: Fracture surfaces of CFRPPs using uneven carbon fibers $\left(80^{\circ} \mathrm{C}\right) .(\mathrm{a}) 1$ day; and (b) 112 days.

Water at the interface between the fiber and polymer matrix penetrated deeply to the center of CFRPP when the water temperature was $50^{\circ} \mathrm{C}$. The surface roughness of carbon fiber was increased by resin particle addition. The interfacial shear strength of CFRPP using uneven carbon fiber after immersion until 28 days might be increased because of anchor effect [13] and increase of surface area of carbon fiber [14] by resin particle addition.

When the water temperature was $80^{\circ} \mathrm{C}$, water absorption of polymer matrix near the surface of carbon fiber in CFRPP occurred rapidly after water penetration. Viscoelasticity and interfacial adhesion property of the polymer matrix near the surface of carbon fiber in CFRPP were decreased extremely by water absorption at $80^{\circ} \mathrm{C}$. Therefore, interfacial shear strength of CFRPP was very improved by the anchor effect of resin particle after water immersion until 28 days at $80^{\circ} \mathrm{C}$. However, interfacial shear strengths of CFRPPs using non-immersed and uneven carbon fibers almost did not change because decrease of viscoelasticity and interfacial adhesion property of polymer matrix under a hot-wet environment for a long term strongly dominated the CFRPP interfacial shear strength.

The results described above showed that the interfacial shear strength of CFRPP using uneven carbon fiber was affected strongly by water absorption of polymer matrix and water 
penetration into the interface between the fiber and matrix under a hot-wet environment up to 28 days. Viscoelasticity and the interfacial adhesion property of polymer matrix under hot-wet environment must be investigated further in future studies.

\section{CONCLUSIONS}

This study examined the interfacial shear strength of CFRPP using uneven carbon fiber under hot-wet environment for the long term. As a result, the interfacial shear strength of CFRPP using even and uneven carbon fiber under all conditions decrease rapidly after immersion for one day. Subsequently, interfacial shear strengths of CFRPP using even and uneven carbon fibers under all conditions decreased slowly with an increase of immersion time until 28 days. However, their interfacial shear strengths changed very little with increased immersion time beyond 56 days. From SEM observations, large resin particles on the carbon fiber fracture surface were found over $50^{\circ} \mathrm{C}$. A lot of matrix material on the fracture surface of CFRPP using uneven carbon fiber at $80^{\circ} \mathrm{C}$ was often found compared with that of CFRPP using uneven carbon fiber at $50^{\circ} \mathrm{C}$. The viscoelasticity and interfacial adhesion property of water absorbing polymer matrix probably became low when CFRPP using uneven carbon fiber was immersed at temperatures higher than $50^{\circ} \mathrm{C}$. Therefore, the interfacial shear strength of CFRPP using uneven carbon fiber strongly affected the water absorption of matrix and water penetration into the interface between the fiber and matrix under a hot-wet environment.

\section{ACKNOWLEDGEMENT}

This study was supported by Mr. M. Nakamura (Sekisui Chemical Co. Ltd.), who supplied uneven carbon fiber.

[1] FOMM Co. Ltd., www.fomm.co.jp/research-en.

[2] Eddy, D.S. \& Sparks, D.R., Application of MEMS technology in automotive sensors and actuators. Proceedings of the IEEE, 86, pp. 1747-1755, 1998.

[3] Katsuta, T., Yoshida, H., Kitaori, K., Ono, H., Iwabe, H. \& Kasa, N., Structure and heat management of the motors developed in Okayama vehicle engineering project for the next EV. Journal of the Japan Society of Applied Electromagnetics and Mechanics, 26, pp. 224-230, 2018. (In Japanese.)

[4] Takahashi, T., Ishikawa, R., Tominaga, R., Aizawa, S. \& Minato, J., Development of epowertrain for small electric vehicles. Panasonic Technical Journal, 64, pp. 63-68, 2018. (In Japanese.)

[5] Arao, Y., Yumitori, S., Suzuki, H., Tanaka, T., Tanaka, K. \& Katayama, T., Mechanical properties of injection-molded carbon fiber/polypropylene hybridized with nanofillers. Composites Part A: Applied Science and Manufacturing, 55, pp. 19-26, 2013.

[6] Enoki, S., Kojima, K., Mizuno, S., Katayama, K. \& Tanaka, K., High-speed compression molding of continuous carbon fiber reinforced polypropylene. WIT Transactions on the Built Environment, vol. 137, WIT Press: Southampton and Boston, pp. 311-315, 2014.

[7] Kim, J.W. \& Lee, J.S., The effect of the melt viscosity and impregnation of a film on the mechanical properties of thermoplastic composites. Materials, 9, pp. 448-463, 2016. 
[8] Tanaka, K., Ohno, K. \& Katayama, T., Effects of modification and processing time on fiber/matrix interfacial strength for carbon fiber reinforced polypropylene. WIT Transactions on the Built Environment, vol. 166, WIT Press: Southampton and Boston, pp. 329-334, 2016.

[9] Tang, J. et al., Discontinuities as a way to influence the failure mechanisms and tensile performance of hybrid carbon fiber/self-reinforced polypropylene composites. Composites Part A: Applied Science and Manufacturing, 107, pp. 354-365, 2018.

[10] Kada, D., Koubaa, A., Tabak, G., Migneault, S., Garnier, B. \& Boudenne, A., Tensile properties, thermal conductivity, and thermal stability of short carbon fiber reinforced polypropylene composites. Polymer Composites, 39, pp. E664-E670, 2018.

[11] Zao, J., Lu, C., Guo, S., Wang, K. \& Fu, Q., Polymorphic structures phase diagram of shear-induced isotactic polypropylene/carbon fiber cylindrites. Materials and Design, 150, pp. 40-48, 2018.

[12] Nguyen-tran, H.D., Hoang, V.T., Do, V.T., Chun, D.M. \& Yum, Y.J., Effect of multiwalled carbon nanotubes on the mechanical properties of carbon fiberreinforced polyamide-6/polypropylene composites for lightweight automotive parts. Materials, 11, pp. 429-441, 2018.

[13] Katogi, H., Takemura, K. \& Mochizuki, M., Effect of water temperature on interfacial shear strength of resin particles added CFRTP. Key Engineering Materials, 774, pp. 7-12, 2018.

[14] Katogi, H. \& Takemura, K., Interfacial shear strength of resin particles added to carbon fiber/maleic anhydride grafted polypropylene in a hot-wet environment. WIT Transactions on Engineering Sciences, vol. 116, WIT Press: Southampton and Boston, pp. 229-307, 2017. 